\title{
p53 regulates cyclophosphamide teratogenesis by controlling caspases 3, 8, 9 activation and NF- $\kappa$ B DNA binding
}

\author{
Olga Pekar, Nataly Molotski, Shoshana Savion, Amos Fein, Vladimir Toder and Arkady Torchinsky \\ Department of Cell and Developmental Biology, Sackler School of Medicine, Tel Aviv University, Ramat Aviv, Tel Aviv \\ 69978, Israel \\ Correspondence should be addressed to A Torchinsky; Email: arkadyt@post.tau.ac.il
}

O Pekar and N Molotski contributed equally to this work

\begin{abstract}
The tumor suppressor protein p53 regulates the sensitivity of embryos to such human teratogens as ionizing radiation, diabetes, and cytostatics. Yet, the molecular mechanisms whereby it fulfills this function remain undefined. We used p53 heterozygous $\left(\mathrm{p53}^{+/-}\right.$) female mice mated with $\mathrm{p53}^{+/-}$males and then exposed to cyclophosphamide (CP) to test whether caspases 3,8 , and 9 and the transcription factor nuclear factor (NF)- $\kappa$ B may serve as p53 targets. Mice were exposed to CP on day 12 of pregnancy and killed on days 15 and 18 of pregnancy to evaluate CP-induced teratogenic effect. The brain and limbs of embryos harvested $24 \mathrm{~h}$ after CP treatment were used to evaluate NF- $\kappa$ B (p65) DNA-binding activity by an ELISA-based method, the activity of the caspases by appropriate colorimetric kits, apoptosis, and cell proliferation by TUNEL, and $5^{\prime}$-bromo-2'-deoxyuridine incorporation respectively. We observed that the activation of caspases 3, 8, and 9 and the suppression of NF- $\mathrm{B}$ DNA binding following CP-induced teratogenic insult took place only in teratologically sensitive organs of p53 ${ }^{+/+}$but not p53 $^{-/-}$embryos. CP-induced apoptosis and suppression of cell proliferation were also more intensive in the former, and they exhibited a higher incidence of structural anomalies, such as open eyes, digit, limb, and tail anomalies. The analysis of the correlations between the p53 embryonic genotype, the activity of the tested molecules, and the CP-induced dysmorphic events at the cellular and organ level suggests caspases 3, 8, and 9 and NF- $\kappa$ B as components of p53-targeting mechanisms in embryos exposed to the teratogen. Reproduction (2007) 134 379-388
\end{abstract}

\section{Introduction}

The ability of the tumor suppressor protein $\mathrm{p} 53$ to regulate teratological sensitivity of embryos has been demonstrated in studies with such diverse teratogens as benzo(a)pyrene (Nicol et al. 1995), 2-chloro-2'-deoxyadenosine (Wubah et al. 1996), 4-hydroperoxycyclophosphamide (Moallem \& Hales 1998), ionizing radiation (Norimura et al. 1996, Wang et al. 2000), and diabetes (Pani et al. 2002). These studies also provided evidence that both p53-mediated apoptosis and p53-mediated cell arrest may be important steps in the pathogenesis of teratogen-induced anomalies. Importantly, however, as in the above studies, the presence of p53 was found to be associated with both the increased and the decreased teratological susceptibility of embryos, they led to the conclusion that p53 is able to act both as a 'teratological suppressor' and as a 'teratological initiator' (Torchinsky et al. 2005).

In such a situation, for the role of p53 in teratogenesis to be clarified, molecules that p53 engages to realize its proapoptotic activity in teratogen-exposed embryos have to be revealed. In addition, there is a need to know whether p53 interacts with molecules that act as regulators of cell proliferation in embryos responding to teratogens. Available data from the literature suggest that these molecules still remain practically undefined. At the same time, those data imply that such molecules as caspases 3, 8, and 9 as well as the transcription factor NF- $\kappa$ B seem to be good candidates for studies addressing these topics. The reasons behind this statement may be briefly formulated as follows.

1. The effector caspase 3 and the initiator caspases 8 and 9 are presently considered as the main executors of apoptosis (Riedl \& Shi 2004). The initiator caspase 9 operates in the mitochondrial pathway, whereas the initiator caspase 8 acts in the death-receptor pathway, while both pathways share the effector caspase 3 (Pommier et al. 2004). Teratological studies revealed that at least one of these caspases is activated in embryos exposed to such teratogens as cyclophosphamide (CP), heat shock, sodium arsenite, diabetes, retinoic acid, methyltriazene (an alkylating agent), and 
ionizing radiation (Torchinsky et al. 2005). The possibility that p53-mediated apoptosis may be associated with the activation of any of the above-mentioned caspases is suggested by the evidence demonstrating the ability of p53 to activate both the extrinsic and the intrinsic apoptotic pathways (Fridman \& Lowe 2003, Pommier et al. 2004, Michalak et al. 2005).

2. The transcription factor NF- $\kappa \mathrm{B}$ is presently considered as a key molecule controlling the apoptosis process, acting mainly as an apoptosis inhibitor (Dutta et al. 2006). NF- $\kappa B$ is transcriptionally active in embryos during the organogenesis stage of development (Beg et al. 1995) and one of its subunits, p65, was shown to act as a powerful inhibitor of tumour necrosis factor $\alpha$-induced physiological apoptosis (Doi et al. 1999, Rosenfeld et al. 2000). There is also considerable evidence demonstrating NF- $\kappa \mathrm{B}$ as an inducer of cell proliferation in cells exposed to toxic stimuli (Chen et al. 2001, Shishodia \& Aggarwal 2004). The involvement of NF- $\mathrm{KB}$ in regulating the teratogenic response has been suggested by the results of studies with such teratogens as CP (Torchinsky et al. 2002, 2003, 2006), alcohol (Acquaah-Mensah et al. 2002), thalidomide (Hansen et al. 2002), diabetes (Torchinsky et al. 2004), and phenytoin (an anticonvulsant drug; Kennedy et al. 2004). Finally, considerable evidence has been presently collected suggesting the existence of the mechanisms by which NF-KB and p53 are able to regulate each other's activity (Webster \& Perkins 1999, Ryan et al. 2000, Pommier et al. 2004).

Therefore, the present study was undertaken to test whether caspases 3,8 , and 9 as well as the transcription factor NF- $\kappa$ B may serve as p53 targets in embryos exposed to teratogenic stress. To that end, we used as a model p53 heterozygous ( ${\mathrm{p} 53^{+/-}}^{+}$) females mated with $\mathrm{p} 53^{+/-}$males and then exposed to such a teratogen as CP and analyzed how parameters such as p53 gene status of embryos, the activity of the tested molecules, apoptosis, cell proliferation, and structural anomalies correlate with each other.

\section{Materials and Methods}

\section{Animals}

Breeding pairs of C57/BL6 p53 knockout mice bearing a mutation deleting $\sim 40 \%$ of the p53-coding region and completely blocking production of p53 protein (Jacks et al. 1994) were received as a gift from Prof. Moshe Oren (Weizmann Institute of Science, Israel) and now a colony of these mice is being maintained in Tel Aviv University Animal Facility on a $14 \mathrm{~h}$ light:10 h darkness cycle with food and tap water ad libitum. To obtain pregnancies,

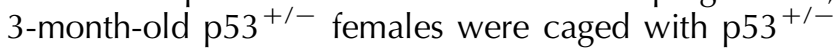
males for $3 \mathrm{~h}$, from 0700 to $1000 \mathrm{~h}$ (darkness) and the presence of a vaginal plug (1100 h) was designated as day 1 of pregnancy. Animal experiments were approved by the Ethics Committee for Animal Use of Tel Aviv University.

\section{Genotyping}

DNA was extracted from the amnion using lysis buffer (0.1 M Tris- $\mathrm{HCl}$ (pH 8.5), $200 \mathrm{mM} \mathrm{NaCl}$, SDS 0.2\%, EDTA $5 \mathrm{mM}$ in double distilled water (DDW)), $0.5 \mathrm{mg} / \mathrm{ml}$ proteinase $\mathrm{K}$ (Sigma), and incubated for $3 \mathrm{~h}$ at $56{ }^{\circ} \mathrm{C}$ following 5-min incubation at $95^{\circ} \mathrm{C}$. PCR was performed using PCR mix (Promega), DNA, and 3 primers (Sigma): 5'-ACAGCGTGGTGGTACCTTAT-3', 5'-TATACTCAGAGCCGGCCT-3', and 5'-CTATCAGGACATAGCGTTGG- ${ }^{\prime}$ (Jacks et al. 1994) under the following conditions: initial preheating at $94{ }^{\circ} \mathrm{C}$ for $3 \mathrm{~min}$ followed by 30 cycles of the following three steps: 1$)$ denaturing $\left(94^{\circ} \mathrm{C}\right)$ for $\left.30 \mathrm{~s}, 2\right)$ annealing $\left(55^{\circ} \mathrm{C}\right)$ for $30 \mathrm{~s}$, and 3 ) extension $\left(72{ }^{\circ} \mathrm{C}\right)$ for $1 \mathrm{~min}$ followed by $3 \mathrm{~min}$ at $72{ }^{\circ} \mathrm{C}$. PCR products were diluted in DNA-loading buffer (10 mM Tris- $\mathrm{HCl}(\mathrm{pH} 7.6)$, bromophenol blue $0.03 \%$, glycerol $60 \%$, xylene cyanole $0.03 \%$, and $60 \mathrm{mMEDTA}$ ) and loaded on $1.2 \%$ agarose gel diluted in TBE buffer (4.5 mM Tris base (pH 6.8), $4.5 \mathrm{mM}$ boric acid, and $0.05 \mathrm{mM}$ EDTA in DDW) with ethidium bromide (Sigma).

\section{Teratological testing}

$\mathrm{CP}$ (Sigma) was injected intraperitoneally at $1000 \mathrm{~h}$ of day 12 of pregnancy at 20 or $30 \mathrm{mg} / \mathrm{kg} \mathrm{CP}$ (in $0.5 \mathrm{ml}$ saline $/ 20 \mathrm{~g}$ body weight). Pregnant females injected with saline $(0.5 \mathrm{ml} / 20 \mathrm{~g}$ body weight) were used as a control throughout the study. To evaluate the CP-induced embryotoxic effect, females were killed on day 18 of pregnancy, the uteri were removed and implantation sites, resorptions and live embryos were recorded. Live fetuses were weighted, fixed in Bouin's solution, and examined for gross structural anomalies. In addition, such indices as the level of embryonic death, fetal weight, and the incidence of fetuses with digit and limb anomalies were evaluated in a group of females exposed to $30 \mathrm{mg} / \mathrm{kg} \mathrm{CP}$ and examined on day 15 of pregnancy.

\section{Apoptosis, cell proliferation, the activity of the caspases, and NF-K $B$ DNA-binding activity}

Apoptosis, cell proliferation, the activity of caspases 3, 8, and 9 as well as NF- $\kappa$ B DNA-binding activity were evaluated in the brain and limbs of embryos harvested $24 \mathrm{~h}$ after $\mathrm{CP}$ treatment (day 13 of pregnancy). The choice of the brain was based on our previous studies (Torchinsky et al. 1995a) suggesting that the intensity of CP-induced apoptosis in this organ directly correlates with the incidence (or severity) of nearly all CP-induced structural anomalies tested in the study. As to the limbs, they were chosen because in this study the limbs of p53 knockout and wild-type embryos were found to differ dramatically in the sensitivity to $\mathrm{CP}$-induced teratogenic insult. 


\section{Apoptosis}

To evaluate apoptosis, three or four embryos obtained from three or four litters of each experimental and control groups were fixed in formaldehyde, dehydrated in alcohol and xylene, and embedded in paraffin. Tissue sections $(7 \mu \mathrm{m})$ were prepared and the localization of apoptotic cells in the tested organs was visualized by TUNEL as described elsewhere (Torchinsky et al. 2003). Briefly, after deparafinization, nuclei were labeled with biotinylated dUTP (Promega) using the TdTenzyme (Promega). Apoptotic cells were detected by streptoavidin-horseradish peroxidase (Promega) followed by development of a color reaction using 3,3'-diaminobenzidine tetrahydrochloride substrate kit (Zymed Laboratory Inc., South San Francisco, CA, USA).

\section{Cell proliferation}

Cell proliferation was evaluated as described elsewhere (Torchinsky et al. 2003). Briefly, pregnant mice were injected intraperitoneally with $5^{\prime}$-bromo-2'-deoxyuridine (BrdU; Sigma) in a dose of $200 \mathrm{mg} / \mathrm{kg}$ in $0.5 \mathrm{ml} \mathrm{PBS} / 20 \mathrm{~g}$ body weight at $0700 \mathrm{~h}$ on day 13 of pregnancy. Three embryos from three different litters were collected $6 \mathrm{~h}$ after $\mathrm{BrdU}$ injection, processed as described above, $7 \mu \mathrm{m}$ paraffin-embedded sections were prepared. The sections were incubated with anti-BrdU antibody (Santa Cruz Biotechnology, Santa Cruz, CA, USA) overnight followed by goat anti-mouse biotinylated antibody (Jackson ImmunoResearch Laboratories Inc., West Grove, PA, USA) for $30 \mathrm{~min}$ and BrdU-positive cells were detected by streptoavidin-horseradish peroxidase (Promega) followed by development of a color reaction using $3,3^{\prime}$-diaminobenzidine tetrahydrochloride substrate kit (Zymed Laboratory).

\section{Caspases activity and NF-KB DNA-binding activity}

To prepare a tested sample of the brain and limbs, embryos collected from three to four litters were pooled. Nuclear and cytoplasmic extracts were prepared using NucBuster Protein Extraction kit (Novagen, San Diego, CA, USA). Protein concentration was measured by Bradford assay using a BIO-RAD Protein Assay (Bio-Rad Laboratories $\mathrm{GmbH}$ ) and a 96-well microplate (Greiner Bio-One International, Frickenhausen, Germany) according to the manufacturer's instructions. Samples were frozen in aliquots in liquid nitrogen and stored at $-70{ }^{\circ} \mathrm{C}$ until use. The activity of caspases 3, 8, and 9 was evaluated in cytoplasmic extracts using appropriate colorimetric kits (MBL International, Woburn, MA, USA) as described elsewhere (Torchinsky et al. 2006). The measurements were performed using a spectrophotometer according to the manufacturer's instructions. The DNA-binding activity was evaluated using the ELISA-based TransAM kit (Active Motif, Carlsbad, CA, USA), which is designed to provide the binding of the NF- $\kappa B$ p 65 subunit to the NF- $\kappa B$ binding consensus sequence 5'-GGGACTTTCC-3', as described elsewhere (Torchinsky et al. 2006). Briefly, $20 \mu$ g nuclear protein were added to the wells. Subsequently, the NF- $\kappa B$ oligonucleotide complex was detected by a primary antibody directed against the active form of the p65 subunit and a horseradish peroxidase-conjugated secondary antibody was added to develop a color reaction that was quantified by spectrophotometry. A wild-type consensus oligonucleotide, provided as a competitor for NF$\kappa \mathrm{B}$ binding, and a mutated consensus oligonucleotide with no effect on NF- $\kappa B$ binding were used in order to monitor the specificity of the assay. All samples were run in duplicate and only samples in which the differences between values obtained in replicates did not exceed $10 \%$ were used to calculate the average value.

\section{Statistical analysis}

The statistical analysis of continuous parameters such as the rate of postimplantation death and fetal weight was performed on a litter basis using the GT2-method for multiple comparisons (Sokal \& Rohlf 1995). The proportion of resorptions per litter was transformed into arcsine values by the Freeman-Tukey's binomial method as described elsewhere (Torchinsky et al. 1995b) and these values were analyzed statistically. For the statistical analysis of dichotomous parameters (structural anomalies), an embryo was used as an independent variable and the $\chi^{2}$ test was run to look for an association across treatment groups and embryonic genotypes as described (Fleiss 1981).

The statistical analysis of data characterizing caspases activity and NF- $\mathrm{BB}$ DNA-binding activity was performed as described elsewhere (Torchinsky et al. 2006). Briefly, five samples obtained from the embryonic brain and limbs of control and experimental groups were tested for caspase activity and for NF-KB DNA-binding activity. Optical density (OD) values registered in control samples were used to calculate the average OD values representing levels of caspase activity or NF-KB DNA binding in

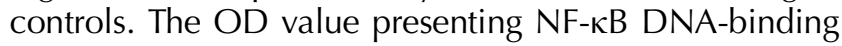
activity in an experimental sample was expressed as a percentage of the average OD value for a corresponding control. The activity of a tested caspase in an experimental sample was expressed as the ratio between the OD value registered in an experimental sample and the average OD value representing the activity of a given caspase in control embryos. The results were analyzed statistically by the GT2-method. The two-tailed level of significance of differences was equal to 0.05 for all tested parameters.

\section{Results}

\section{Teratogenic response to $C P$}

The final manifestations of the $\mathrm{CP}$-induced teratogenic stress are postimplantation embryonic death, fetal weight reduction, and structural anomalies. We observed that in 
females treated with $30 \mathrm{mg} / \mathrm{kg} \mathrm{CP}$ and examined on day 18 of pregnancy (Table 1), the level of postimplantation death reached $\sim 37 \%$ being significantly increased when comparing with that registered in controls $(\sim 8 \%)$. The striking departure from the Mendelian 25\%:50\%:25\% genotype ratio ( $\sim 33 \%: 65 \%: 2 \%)$ was also registered in these females. In females treated with $20 \mathrm{mg} / \mathrm{kg} \mathrm{CP}$, the level of postimplantation death $(\sim 13 \%)$ was nearly twice as high as that in controls but the difference was statistically insignificant (Table 1).

Both doses of CP expectedly induced strong fetal growth retardation (Table 1), and this effect was also found to be p53-genotype dependent. Thus, the weight of $\mathrm{p} 53^{-1-}$ fetuses of females treated with $20 \mathrm{mg} / \mathrm{kg}$ $(0.51 \pm 0.01 \mathrm{~g})$ was significantly higher than that of $\mathrm{p} 53^{+/+}$and $\mathrm{p} 53^{+/-}$fetuses $(0.37 \pm 0.04$ and $0.42 \pm$ $0.01 \mathrm{~g}$ respectively). The weight of two live $\mathrm{p} 53^{-I-}$ fetuses observed in litters of mice treated with $30 \mathrm{mg} / \mathrm{kg}$ was also visibly higher than the weight of $\mathrm{p53}^{+/+}$and p53 $3^{+/-}$fetuses (Table 1).

$\mathrm{p} 3^{+/+}$and $\mathrm{p} 53^{+/-}$fetuses treated with $20 \mathrm{mg} / \mathrm{kg} \mathrm{CP}$ exhibited an identical pattern of structural anomalies, which, in turn, differed significantly from that registered in p53 ${ }^{-1-}$ fetuses (Fig. 1). Thus, the incidence of such anomalies as ectrodactyly, kinky or short tail, open eyes was significantly higher in $\mathrm{p} 53^{+/+}$than that in $\mathrm{p} 53^{-/-}$ fetuses. Also, $\sim 40$ and $35 \%$ of $\mathrm{p} 53^{+/+}$fetuses exhibited adactyly and hemimelia respectively, but no $\mathrm{p} 53^{-1-}$ fetuses with those anomalies were registered. On the contrary, no $\mathrm{p} 53^{+/+}$fetuses with exencephaly were observed, whereas $33 \%$ of $\mathrm{p} 53^{-1-}$ fetuses exhibited this anomaly. Finally, no anomalies identical to those induced by $\mathrm{CP}$ were observed in control $\mathrm{p} 53^{+/+}$and $\mathrm{p} 53^{+/-}$ fetuses, whereas two control p53 $3^{-1-}$ fetuses $(\sim 11 \%)$ had exencephaly.

As we expected, the incidence of the tested anomalies was higher in $\mathrm{p} 53^{+/+}$and $\mathrm{p} 53^{+/-}$fetuses treated with $30 \mathrm{mg} / \mathrm{kg}$ CP when comparing with that registered in those embryos treated with $20 \mathrm{mg} / \mathrm{kg} \mathrm{CP}$ (data not shown). However, as only two $\mathrm{p} 53^{-1-}$ fetuses were observed in litters of mice treated with $30 \mathrm{mg} / \mathrm{kg}$ CP (Table 1), we could not evaluate their teratogenic response to this dose of CP. Also, it seemed to be important to outline the period of development when CP-treated $\mathrm{p} 53^{-/-}$embryos die. To that end, mice treated with $30 \mathrm{mg} / \mathrm{kg}$ were examined on day 15 of pregnancy (the end of the organogenesis period).

We observed (Table 2) that at this time point, the level of postimplantation death was obviously increased in CP-treated mice, reaching $\sim 23 \%$ vs $5 \%$ in controls. At the same time, the genotype ratio did not deviate from the expected Mendelian ratio 1:2:1. It has also been observed that 15-day embryos of CP-treated mice were retarded in development, and the extent of the growth retardation was significantly higher in $\mathrm{p} 53^{+/+}$and $\mathrm{p} 53^{+/-}$than in p53 ${ }^{-1-}$ embryos (Table 2). Finally, teratological testing revealed that $\mathrm{p} 53^{-1-}$ and $\mathrm{p} 53^{+/+}$embryos differed dramatically with respect to their sensitivity to CP-induced digit and limb deformities. Indeed, whereas,

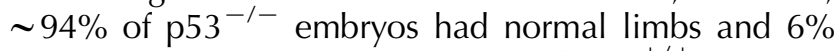
exhibited ectrodactyly, only $\sim 6 \%$ of ${\mathrm{p} 53^{+/+}}^{+1}$ embryos had normal limbs and $94 \%$ exhibited either adactyly or ectrodactyly. Remarkably, the frequency of all these anomalies in $\mathrm{p} 53^{+/-}$embryos did not differ significantly from that registered in $\mathrm{p} 53^{+/+}$embryos.

Thus, teratological testing revealed that the response of p53 $3^{-1-}$ embryos to CP-induced embryolethal and teratogenic stimuli strikingly differed from that demonstrated by $\mathrm{p} 3^{+/+}$and $\mathrm{p} 53^{+/-}$embryos, which turned out to be equally sensitive to the teratogen. Therefore, in the following experiments, we tried to evaluate whether CP-treated $\mathrm{p} 53^{+/+}$and $\mathrm{p} 53^{-/-}$embryos differ from each other with respect to such indices as caspase activity, NF$\kappa \mathrm{B}$ (p65 subunit) DNA binding, cell proliferation as well as apoptosis. To that end, we evaluated these indices in two teratologically sensitive embryonic structures, the brain and limbs, of embryos harvested $24 \mathrm{~h}$ after CP treatment.

Table 1 Reproductive performance of $\mathrm{p} 53^{+/-}$females treated with cyclophosphamide (CP) and tested on day 18 of pregnancy.

\begin{tabular}{|c|c|c|c|}
\hline \multirow[b]{2}{*}{ Indices } & \multicolumn{3}{|c|}{ Treatment } \\
\hline & Controls & $\mathrm{CP}(20 \mathrm{mg} / \mathrm{kg})$ & $\mathrm{CP}(30 \mathrm{mg} / \mathrm{kg})$ \\
\hline Number of litters & 10 & 17 & 17 \\
\hline Implantation sites/litter & $85 / 8.5$ & $133 / 7.8$ & $141 / 8.3$ \\
\hline Percent of postimplantation loss (arcsine, mean \pm s.E.M.) & $7.9 \pm 2.4(18.2 \pm 2.3)^{*}$ & $12.9 \pm 3.2(21.6 \pm 2.5)^{*}$ & $36.9 \pm 5.7(39.2 \pm 4.7)^{+}$ \\
\hline \multicolumn{4}{|l|}{ Number of live fetuses } \\
\hline Total & 78 & 117 & $89^{\|}$ \\
\hline $\mathrm{p} 53^{+/+}$ & $22(28.2 \%)$ & $35(29.9 \%)$ & $29(32.6 \%)$ \\
\hline p53 1 - & $37(47.4 \%)$ & $63(53.9 \%)$ & $58(65.2 \%)$ \\
\hline $\mathrm{p} 53^{-1-}$ & $19(24.4 \%)$ & $19(16.2 \%)$ & $2(2.2 \%)$ \\
\hline \multicolumn{4}{|l|}{ Weight of fetuses (g, mean \pm s.E.M.) } \\
\hline $\mathrm{p} 53^{+1+}$ & $0.70 \pm 0.06^{*}$ & $0.37 \pm 0.04^{+, \S}$ & $0.27 \pm 0.06^{\S}$ \\
\hline p53 $3^{+/-}$ & $0.66 \pm 0.04^{*}$ & $0.42 \pm 0.01^{\dagger}$ & $0.27 \pm 0.02^{\S}$ \\
\hline $\mathrm{p} 53^{-1-}$ & $0.67 \pm 0.08^{*}$ & $0.51 \pm 0.01^{\ddagger}$ & $0.38,0.44^{\mathrm{a}}$ \\
\hline
\end{tabular}

Means not sharing common superscripts are significantly different. The two-tailed level of significance of differences was equal to 0.05 . "Statistically significant $(P<0.05)$ departure from Mendelian 25\%:50\%:25\% genotype ratio.

${ }^{a}$ The weight of two live $\mathrm{p} 53^{-1-}$ fetuses. 


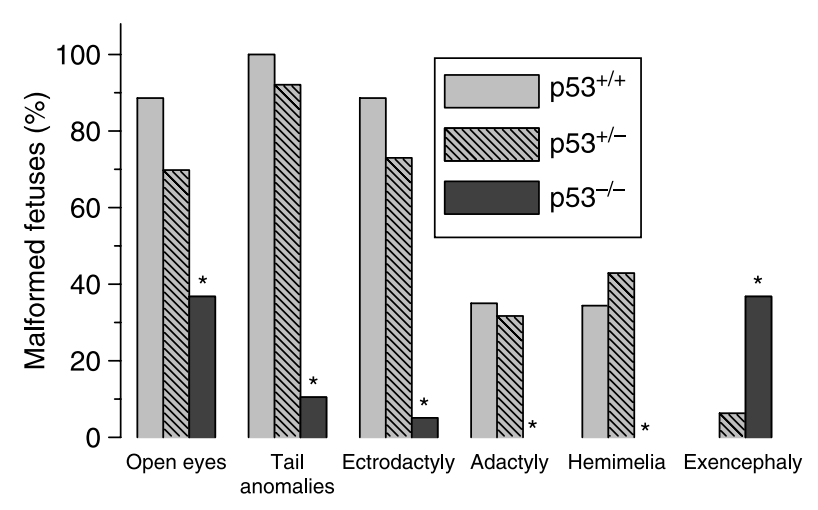

Figure 1 Teratogenic effect of CP. Females were treated with $20 \mathrm{mg} / \mathrm{kg}$ $\mathrm{CP}$ on day 12 of pregnancy. Thirty-five $\mathrm{p} 53^{+/+}$, sixty-three $\mathrm{p} 53^{+/-}$, and nineteen $\mathrm{p} 53^{-1-}$ fetuses were examined for gross structural anomalies on day 18 of pregnancy. An embryo was used as an independent variable and the $\chi^{2}$ test was run to look for an association across embryonic genotypes as described (Fleiss 1981). *Differences are statistically significant $(P<0.05)$ between the percentage of $\mathrm{p} 53^{-1-}$ fetuses having a given anomaly and the percentage of $\mathrm{p} 53^{+/+}$and $\mathrm{p} 53^{+/-}$fetuses with the same anomaly.

\section{Caspase activity}

Caspase 3

An approximately sevenfold increase in caspase 3 activity was registered in the brain of $\mathrm{p} 53^{+/+}$embryos treated with $20 \mathrm{mg} / \mathrm{kg}$ CP and a nearly tenfold increase was observed in embryos treated with $30 \mathrm{mg} / \mathrm{kg}$ (Fig. 2A). In contrast, the activity of the caspase in the brain of $\mathrm{p} 53^{-/-}$embryos treated with both 20 and $30 \mathrm{mg} / \mathrm{kg}$ CP did not differ significantly from that registered in controls. In the limbs of

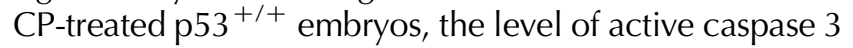
was also statistically significantly higher than that in controls, but its activity did not increase in the limbs of CP-treated p53 $3^{-1-}$ embryos (Fig. 2A).

\section{Caspase 8}

Treatment with CP increased caspase 8 activity in the brain of $\mathrm{p} 53^{+/+}$embryos in a dose-dependent fashion (Fig. 2B).
In the limbs of these embryos, the level of active caspase 8 was also significantly higher than that in controls. However, a statistically significant increase in the level of caspase 8 activity was detected neither in the brain nor in the limbs of CP-treated p53 $3^{-/-}$embryos (Fig. 2B).

\section{Caspase 9}

A statistically significant, approximately threefold increase in the level of caspase 9 activity was detected in the brain of $\mathrm{p} 53^{+/+}$embryos treated with both doses of CP (Fig. 2C). In the limbs of these embryos, the level of caspase 9 activity was also statistically significantly higher than in controls (Fig. 2C). At the same time, in both tested organs of CP-treated p53 $3^{-1-}$ embryos, the level of caspase 9 activity did not differ from that in controls.

\section{NF-KB (p65) DNA binding}

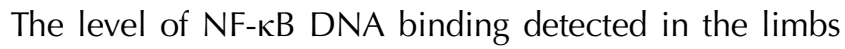
and brain of control embryos did not differ significantly and was p53 genotype-independent (data not shown). At the same time, the level of NF- $\kappa B$ DNA binding in the brain of p53 $3^{+/+}$embryos treated with 20 and $30 \mathrm{mg} / \mathrm{kg}$ $\mathrm{CP}$ was found to be $\sim 65$ and $75 \%$ of that registered in controls respectively (Fig. 2D). These levels did not statistically differ from each other but they differed significantly from the control level. In the limbs of CP-treated wild-type embryos, the level of NF-кB DNA binding was also statistically significantly lower than that in controls. In contrast, in both tested organs of CP-treated p53 ${ }^{-/-}$embryos, the level of NF- $\kappa$ B DNA binding varied in a range between 95 and $105 \%$ of that registered in controls (Fig. 2D).

\section{Apoptosis}

Treatment with both doses of CP expectedly increased the amount of TUNEL-positive nuclei in the brain and limbs of p53 $3^{+/+}$embryos and this amount seemed to be higher in

Table 2 Reproductive performance of $\mathrm{p} 3^{+/-}$females treated with cyclophosphamide (CP) and tested on day 15 of pregnancy.

\begin{tabular}{|c|c|c|}
\hline \multirow[b]{2}{*}{ Indices } & \multicolumn{2}{|c|}{ Treatment } \\
\hline & Controls & $30 \mathrm{mg} / \mathrm{kg} \mathrm{CP}$ \\
\hline Number of litters & 8 & 10 \\
\hline Implantation sites/litter & $66 / 8.2$ & $84 / 8.4$ \\
\hline Percentage of postimplantation loss (arcsine, mean \pm S.E.M.) & $5.1 \pm 3.1(14.3 \pm 3.3)^{*}$ & $22.8 \pm 11.4(27.1 \pm 7.5)^{\dagger}$ \\
\hline \multicolumn{3}{|l|}{ Number of live fetuses } \\
\hline Total & 63 & 64 \\
\hline $\mathrm{p} 53^{+/+}$ & $17(27.0 \%)$ & $17(26.5 \%)$ \\
\hline $\mathrm{p} 53^{+/-}$ & $30(47.6 \%)$ & $31(48.5 \%)$ \\
\hline $\mathrm{p} 53^{-1-}$ & $16(25.4 \%)$ & $16(25.0 \%)$ \\
\hline \multicolumn{3}{|l|}{ Weight of fetuses ( $g$, mean \pm S.E.M.) } \\
\hline $\mathrm{p} 53^{+1+}$ & $0.20 \pm 0.01 *$ & $0.08 \pm 0.01^{\dagger}$ \\
\hline $\mathrm{p} 53^{+/-}$ & $0.21 \pm 0.01 *$ & $0.08 \pm 0.01^{\dagger}$ \\
\hline p55 $3^{-1-}$ & $0.19 \pm 0.01 *$ & $0.13 \pm 0.01^{\ddagger}$ \\
\hline
\end{tabular}

Means not sharing common superscripts are significantly different. The two-tailed level of significance of differences was equal to 0.05 . 

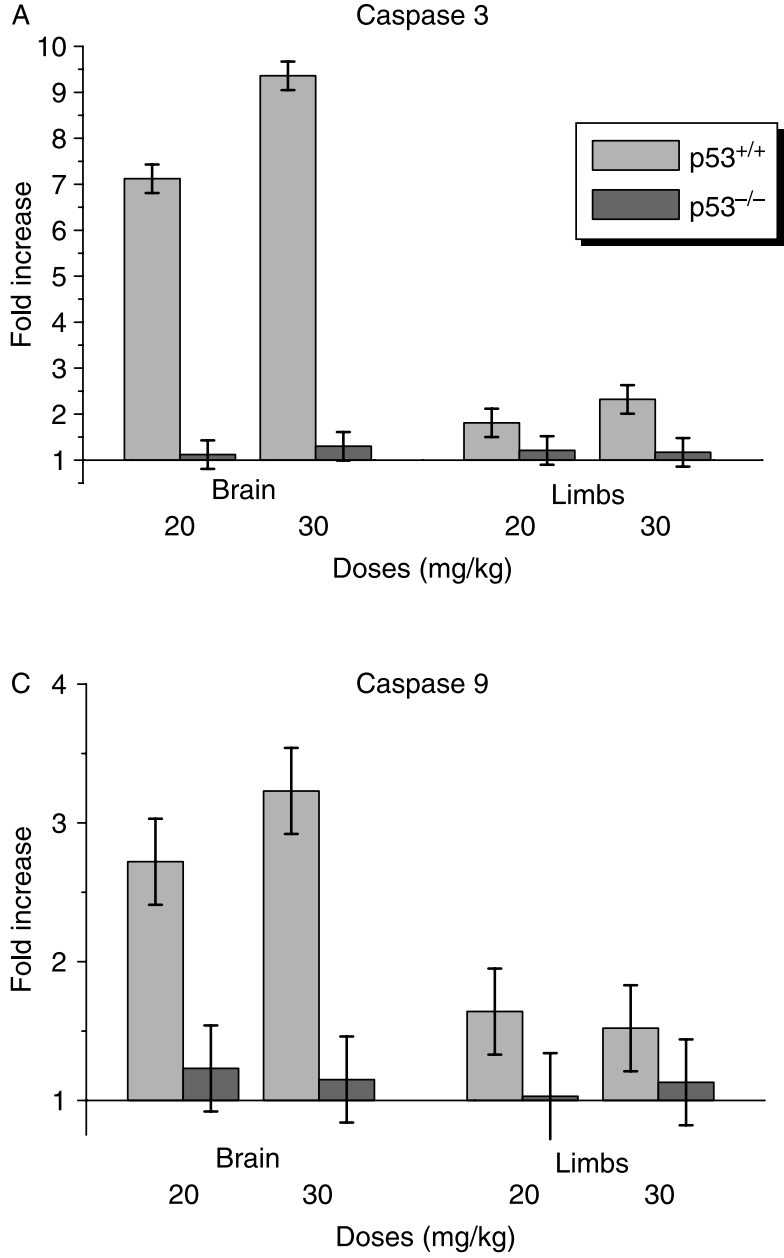

B
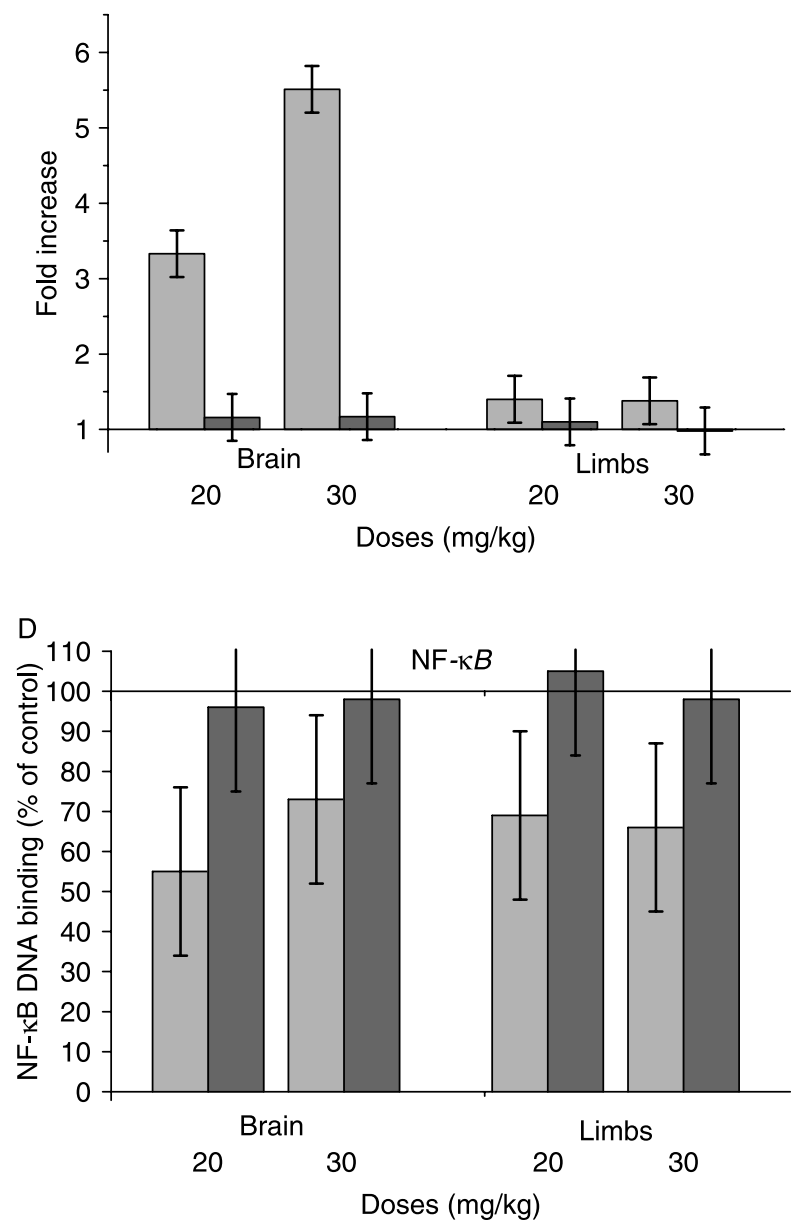

Figure 2 NF- $\mathrm{KB}$ DNA binding and activity of caspases 3, 8, and 9 in the brain and limbs of embryos exposed to CP. Results characterizing the amount of NF- $\kappa B$ DNA binding are presented as $95 \%$ comparison intervals for the means ( $n=5$, all samples were run in duplicate), which are percentages of the average level of NF-KB DNA binding in control samples. Results characterizing caspase activity are presented as $95 \%$ comparison intervals for the means ( $n=5$, all samples were run in duplicate), which are the ratio (fold increase) between the OD value registered in an experimental sample and the average OD value representing the activity of a given caspase in control embryos. Means with intervals that do not overlap are significantly different. Means with upper intervals not reaching $100 \%$ (the amount of NF-KB DNA binding in controls) and means with lower intervals $>1$ (the activity of the caspases in controls) differ significantly from controls.

embryos exposed to the higher dose of $\mathrm{CP}$ (Fig. 3A and B). At the same time, the amount of TUNEL-positive nuclei in the brain and limbs of $\mathrm{p} 53^{-/-}$embryos was visibly lower than that of equally treated $\mathrm{p} 53^{+/+}$embryos. No p53 genotype-dependent differences in the intensity of the physiological apoptosis were revealed, with only single TUNEL-positive nuclei detecting in the tested regions of $\mathrm{p} 53^{+/+}$and $\mathrm{p} 53^{-/-}$control embryos (data not shown).

\section{Cell proliferation}

The amount of BrdU-positive cells in the brain and limbs of CP-treated embryos was definitely lower than that in controls (Fig. 3C and D). In the brain of p53 $3^{+/+}$embryos treated with both doses of $\mathrm{CP}$, the amount of BrdU-positive cells was visibly lower than that in the brain of CP-treated p53 ${ }^{-1-}$ embryos (Fig. 3C). While comparing limbs of wild-type and p53-deficient embryos, a trend toward the decrease in the rate of $\mathrm{BrdU}$ incorporation seemed to take place in wild-type embryos exposed to $20 \mathrm{mg} / \mathrm{kg}$, and this rate was obviously lower in the former exposed to $30 \mathrm{mg} / \mathrm{kg}$ CP (Fig. 3D). No p53 genotype-dependent differences in the level of BrdU labeling were observed in the brain and limbs of control embryos (data not shown).

\section{Discussion}

We observed that the activation of caspases 3, 8, and 9 and the suppression of NF- $\kappa \mathrm{B}$ DNA binding following $\mathrm{CP}$-induced teratogenic insult took place only in teratologically sensitive organs, the brain and limbs, of $\mathrm{p} 53^{+/+}$but not $\mathrm{p} 53^{-1-}$ embryos. In the light of those observations, a pivotal question that needed to be answered was whether p53-mediated activation of the caspases and suppression 

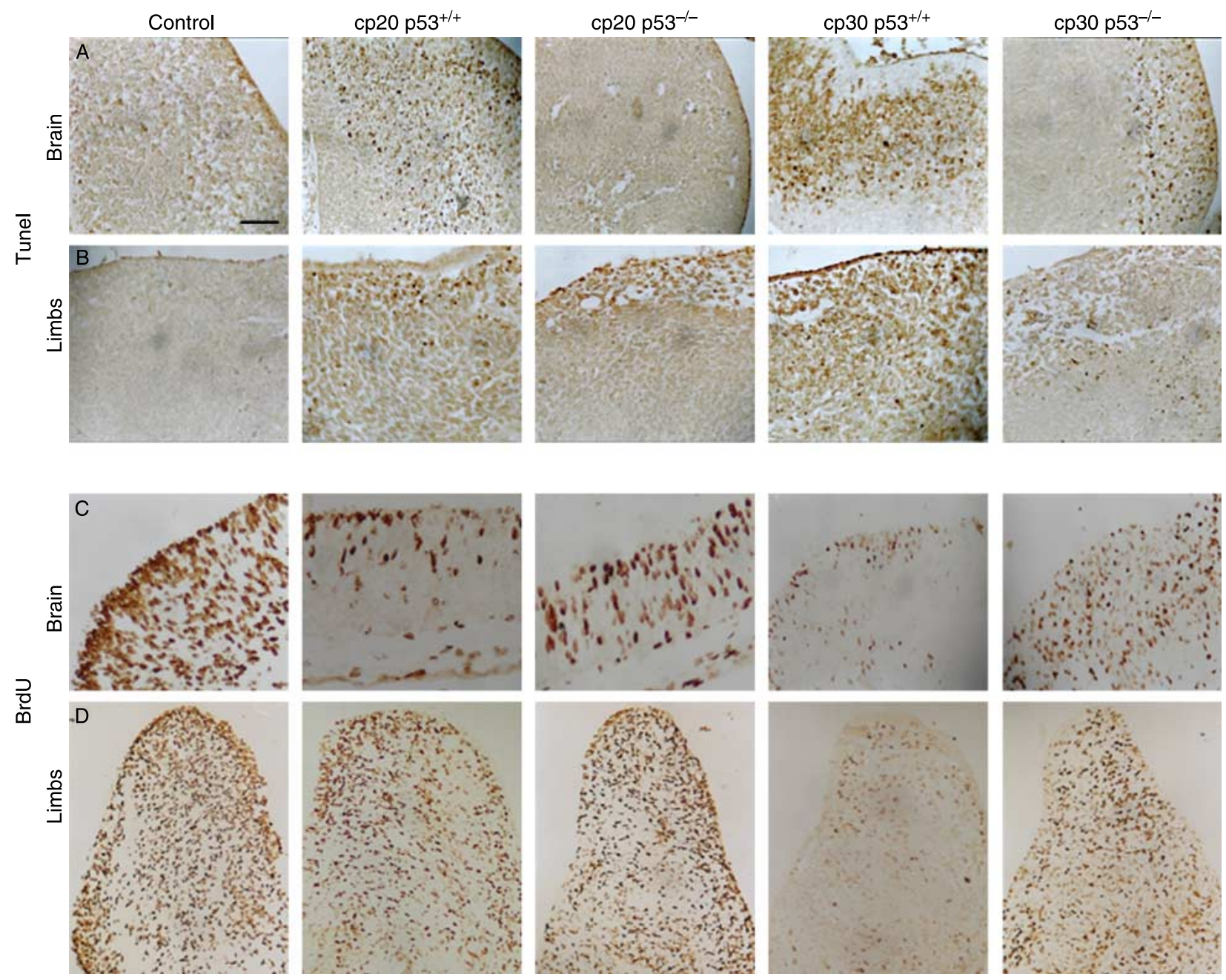

Figure 3 Representative TUNEL- and BrdU-stained sections of the brain and limbs of two embryos exposed to CP. Four midsagittal sections of the brain and four to five sagittal sections of three limbs from three different CP-treated and control p $53^{+/+}$and p53 ${ }^{-1-}$ embryos from four different litters were analyzed. Scale bar: $91 \mu \mathrm{m}$.

of NF-KB DNA binding have functional significance for p53 functioning as a teratological regulator. We tried to answer this question by analyzing how CP-induced dysmorphic events at the organ and cellular level and the p53 embryonic genotype correlate with each other.

In this study, the incidence of most tested anomalies was found to be higher in wild-type than in p53-deficient fetuses, suggesting that p53 functions as a 'teratological initiator'. The only exception is such an anomaly as exencephaly with respect to which p53 seemingly acts as a 'teratological suppressor'. What can be the reasons for this contradiction?

One of the possible explanations is that in the present and other studies (Armstrong et al. 1995, Sah et al. 1995), $10-12 \%$ of in vivo developing p53 knockout fetuses exhibited spontaneous exencephaly. These findings suggest that p53 is indispensable for normal development of the brain, and, consequently, in embryos bearing p53 deletion, there are pathways acting to disturb brain organogenesis. If so, the possibility becomes conceivable that the brain of p53-deficient embryos might be more sensitive to the teratogen than other embryonic structures the development of which are independent of functional p53.

Interestingly, this explanation is consistent with a wellknown situation in teratology, in which a teratogenic agent increases the frequency of a spontaneously occurring defect above its usual incidence (Wilson 1977). Furthermore, the explanation seems to eliminate contradictions in results observed in this study and a study performed earlier in cultured embryonic limbs of p53-deficient murine embryos exposed to an active analog of $\mathrm{CP}$, 4-hydroperoxycyclophosphamide (Moallem \& Hales 1998). Indeed, unlike our work, in which the presence of p53 was associated with an increase in the incidence and severity of limb deformities, cultured limbs of wild-type embryos were found to be more resistant to the teratogen than those of p53-deficient embryos. However, in our study, no spontaneous limb anomalies were observed in 
p53-deficient embryos, whereas 20\% of p53-deficient limbs cultured in the normal medium turned out to be malformed, suggesting that p53 is indispensable for normal development of limbs cultured in those conditions.

Certainly, specific studies need to be performed to prove the correctness of this explanation. Nevertheless, given this explanation and the results of our study, it seems possible to suggest that, at least in CP-treated in vivo developing embryos, p53 acts as a 'teratological initiator'.

A body of studies suggests that the pathogenesis of CP-induced developmental structural anomalies includes intermediate steps such as excessive apoptosis and suppression of cell proliferation (Chernoff et al. 1989, Francis et al. 1990, Little \& Mirkes 1992, Torchinsky et al. 1995a, 1999). In this work, CP-induced apoptosis was evaluated by the TUNEL assay and by measuring the levels of active caspases 3, 8, and 9 . The specificity of the TUNEL technique for the identification of apoptotic cells is somewhat questioned by evidence demonstrating that it also labels necrotic cells (Hughes 2003). At the same time, the activation of the initiator and executioner caspases is presently suggested as a biochemical hallmark of apoptosis, almost never involved in necrosis (Zong \& Thompson 2006).

We observed that the intensity of TUNEL staining in both tested organs of CP-treated wild-type embryos was significantly higher than that in controls, and, importantly, it was also higher in wild-type than in p53 knockout embryos. Also, the levels of active caspases 3, 8, and 9 were higher in embryos demonstrating a more intense TUNEL staining. Together, these data seem to allow concluding that $\mathrm{CP}$-induced apoptosis was more intensive in wild-type than in p53 knockout embryos. In turn, results of BrdU staining suggest that $\mathrm{CP}$ suppresses cell proliferation in embryos and the extent of this suppression was higher in the tested organs of wild-type embryos than in those of their p53 knockout counterparts.

Given that p53 acts as a 'teratological initiator', the above results allow the proposal of a scenario whereby p53 controls the process of CP-induced dysmorphogenesis, acting as a positive regulator of $\mathrm{CP}$-induced apoptosis and suppression of cell proliferation.

Considerable evidence presently exists implicating such molecules as the effector caspases 3, 6, and 7 and the initiator caspases 8 and 9 in the pathways underlying CP-induced apoptosis (Mirkes \& Little 1998, 2000, Huang \& Hales 2002, Little \& Mirkes 2002, Torchinsky et al. 2002, 2006, Little et al. 2003). Results of this study demonstrating activation of caspases 3, 8, and 9 in the brain and limbs of CP-treated embryos are generally consistent with those obtained in the above studies. Besides, as the caspases were activated only in wild-type embryos, they suggest that caspases 3,8 , and 9 may be components of the apoptotic effector machinery engaged by $\mathrm{p} 53$ to mediate teratogen-induced apoptosis.

As mentioned earlier, NF- $\kappa B$ is transcriptionally active in the organogenesis stage embryos and previous studies
(Torchinsky et al. 2002, 2003, 2006) suggest that the suppression of NF-KB DNA-binding activity may be a pathogenetic event for $\mathrm{CP}$ teratogenesis. The transcription factor has a potential of both activating cell proliferation and suppressing apoptosis. Both these activities are beneficial for embryos exposed to teratogens, which, like $\mathrm{CP}$, activate apoptosis and suppress cell proliferation. Therefore, the observation that p53 mediates CP-induced suppression of NF-KB DNA binding seems consistent with the above scenario depicting the function of p53 as a 'teratological initiator'. However, the delineation of functional role for NF- $\mathrm{KB}$ in this scenario is quite problematic because for this it is necessary to know whether NF- $\mathrm{KB}$ regulates the teratogenic response to $\mathrm{CP}$ by influencing cell proliferation or/and apoptosis. Nevertheless, our recent work suggests that the ability of embryos to resist $\mathrm{CP}$-induced teratogenic stress may, to a significant extent, be attributed to the ability of NF- $\kappa B$ to act as a positive regulator of cell proliferation (Molotski et al. in preparation). Given such a suggestion, this study, while demonstrating that $\mathrm{CP}$-induced suppression of NF$\kappa \mathrm{B}$ DNA binding is mediated by $\mathrm{p} 53$, implies NF- $\kappa \mathrm{B}$ as a new important component of the mechanism which p53 engages to regulate induced teratogenesis.

In conclusion, this study supports previous observations demonstrating p53 as a powerful regulator of teratological susceptibility of embryos. In parallel, it implies such molecules as caspases 3, 8, and 9 as well as the transcription factor NF- $\kappa$ B as components of p53targeting mechanisms in embryos exposed to teratogens. Importantly, all the above molecules are presently considered as key components of the apoptotic machinery, with considerable evidence demonstrating $\mathrm{NF}-\kappa \mathrm{B}$ also as a potent positive regulator of cell proliferation. Therefore, studies addressing to what extent and how the ability of p53 to interact with these molecules depends on such factors as the nature of the teratogenic agent, the developmental stage at the time of teratogenic exposure and the intensity of exposure could contribute to our understanding of mechanisms determining teratological sensitivity of embryos. In this context, it is worth noting that in the present study, p53 functioned as a suppressor of CP-induced embryonic death. As p53deficient embryos tested at the end of the organogenesis (day 15 of pregnancy) had greater weight and were less malformed than their wild-type counterparts, and they died, mainly, from this day onward, this result suggests that the mechanism (s) underlying the death of CP-treated p53-deficient embryos differ from those underlying CP-induced growth retardation and structural anomalies. It is possible that studies in such a model as 'embryo exposed to teratogen' might help in understanding what pattern of p53 targeting mechanisms leads to the death of an affected cell population and what pattern protects the population and contributes to its renewal. In vivo models seem to be worth choosing first for these studies. 


\section{Acknowledgements}

This work was supported by grant 6234-1 from The Israel Ministry of Health. The authors declare that there is no conflict of interest that would prejudice the impartiality of this scientific work.

\section{References}

Acquaah-Mensah GK, Kehrer JP \& Leslie SW 2002 In utero ethanol suppresses cerebellar activator protein-1 and nuclear factor- $\mathrm{KB}$ transcriptional activation in a rat fetal alcohol syndrome model. Journal of Pharmacology and Experimental Therapeutics 301 277-283.

Armstrong JF, Kaufman MH, Harrison DJ \& Clarke AR 1995 Highfrequency developmental abnormalities in p53-deficient mice. Current Biology 5 931-936.

Beg AA, Sha WC, Bronson RT, Ghosh S \& Baltimore D 1995 Embryonic lethality and liver degeneration in mice lacking the RelA component of NF-кB. Nature 376 167-170.

Chen F, Castranova V \& Shi X 2001 New insights into the role of nuclear factor- $\mathrm{KB}$ in cell growth regulation. American Journal of Pathology 159 387-397.

Chernoff NJ, Rogers M, Alles AJ, Zucker RM, Elstein KH, Massaro EJ \& Sulik KK 1989 Cell cycle alterations and cell death in cyclophosphamide teratogenesis. Teratogenesis, Carcinogenesis, and Mutagenesis 9 199-209.

Doi TS, Marino MW, Takahashi T, Yoshida T, Sakakura T, Old LJ \& Obata Y 1999 Absence of tumor necrosis factor rescues RelAdeficient mice from embryonic lethality. PNAS 96 2994-2999.

Dutta J, Fan Y, Cupta N, Fan G \& Gelinas C 2006 Current insights into the regulation of programmed cell death by NF-KB. Oncogene $\mathbf{2 5}$ 6800-6816.

Fleiss JL 1981 Statistical Methods for Rates and Proportions, 2nd edn. New York: Wiley.

Francis BM, Rogers JM, Sulik KK, Alles AJ, Elstein KH, Zucker RM, Massaro EJ, Rosen MB \& Chernoff N 1990 Cyclophosphamide teratogenesis: evidence for compensatory responses to induced cellular toxicity. Teratology 42 473-482.

Fridman JS \& Lowe SW 2003 Control of apoptosis by p53. Oncogene 22 9030-9040.

Hansen JM, Gong SG, Philbert M \& Harris C 2002 Misregulation of gene expression in the redox-sensitive NF- $\kappa B$-dependent limb outgrowth pathway by thalidomide. Developmental Dynamics 225 186-194.

Huang C \& Hales BF 2002 Role of caspases in murine limb bud cell death induced by 4-hydroperoxycyclophosphamide, an activated analog of cyclophosphamide. Teratology 66 288-299.

Hughes SE 2003 Detection of apoptosis using in situ markers for DNA strand breaks in the failing human heart. Fact or epiphenomenon? Journal of Pathology 201 181-186.

Jacks T, Remington L, Williams BO, Schmitt EM, Halachmi S, Bronson RT \& Weinberg RA 1994 Tumor spectrum analysis in p53-mutant mice. Current Biology 4 1-7.

Kennedy JC, Memet S \& Wells PG 2004 Antisense evidence for nuclear factor-KB-dependent embryopathies initiated by phenytoin-enhanced oxidative stress. Molecular Pharmacology 66 404-412.

Little SA \& Mirkes PE 1992 Effects of 4-hydroperoxyceclophosphamide (4-OOH-CP) and 4-hydroperoxydechloroclophosphamide (4-OOHdeCLPH) on the cell cycle of post implantation rat embryos. Teratology 45 163-173.

Little SA \& Mirkes PE 2002 Teratogen induced activation of caspase-9 and the mitochondrial apoptotic pathway in early postimplantation mouse embryos. Toxicology and Applied Pharmacology 181 142-151.

Little SA, Kim WK \& Mirkes PE 2003 Teratogen-induced activation of caspase- 6 and caspase- 7 in early postimplantation mouse embryos. Cell Biology and Toxicology 19 215-226.
Michalak E, Villunger A, Erlacher M \& Strasser A 2005 Death squads enlisted by the tumor suppressor p53. Biochemical and Biophysical Research Communications 331 786-798.

Mirkes PE \& Little SA 1998 Teratogen induced cell death in postimplantation mouse embryos: differential tissue sensitivity and hallmarks of apoptosis. Cell Death and Differentiation 5 592-600.

Mirkes PE \& Little SA 2000 Cytochrome $c$ release from mitochondria of early postimplantation murine embryos exposed to 4-hydroperoxycyclophosphamide, heat shock, and staurosporine. Toxicology and Applied Pharmacology 162 197-206.

Moallem SA \& Hales BF 1998 The role of p53 and cell death by apoptosis and necrosis in 4-hydroperoxycyclophosphamide-induced limb malformations. Development 125 3225-3234.

Nicol CJ, Harrison ML, Laposa RR, Gimelshtein I \& Wells PG 1995 A teratologic suppresser role for p53 in benzo[a]pyrene-treated transgenic p53-deficient mice. Nature Genetics 10 181-187.

Norimura T, Nomoto S, Katsuki M, Gondo Y \& Kondo S 1996 p53dependent apoptosis suppresses radiation-induced teratogenesis. Nature Medicine 2 577-580.

Pani L, Horal M \& Loeken MR 2002 Rescue of neural tube defects in Pax3-deficient embryos by p53 loss of function: implications for Pax-3dependent development and tumorigenesis. Genes and Development 16 676-680.

Pommier Y, Sordet O, Antony S, Haywrd RL \& Kohn KW 2004 Apoptosis defects and chemotherapy resistance: molecular interaction maps and networks. Oncogene 23 2934-2949.

Riedl SJ \& Shi Y 2004 Molecular mechanisms of caspase regulation during apoptosis. Nature Reviews. Molecular Cell Biology 5 897-907.

Rosenfeld ME, Prichard L, Shiojiri N \& Fausto N 2000 Prevention of hepatic apoptosis and embryonic lethality in RelATTNFR-1 double knockout mice. American Journal of Pathology 56 997-1007.

Ryan KM, Ernst MK, Rice NR \& Vousden KH 2000 Role of NF-KB in p53mediated programmed cell death. Nature 404 892-897.

Sah VP, Attardi LD, Mulligan GJ, Williams BO, Bronson RT \& Jacks T 1995 A subset of p53-deficient embryos exhibit exencephaly. Nature Genetics 10 175-180.

Shishodia S \& Aggarwal BB 2004 Nuclear factor-кB activation mediates cellular transformation, proliferation, invasion angiogenesis and metastasis of cancer. Cancer Treatment and Research 119 139-173.

Sokal RR \& Rohlf FJ 1995 Biometry, 3rd edn. New York: Freeman and Company.

Torchinsky A, Savion S, Gorivodsky M, Shepshelovich J, Zaslavsky Z, Fein A \& Toder V 1995a Cyclophosphamideinduced teratogenesis in ICR mice: the role of apoptosis. Teratogenesis, Carcinogenesis, and Mutagenesis 15 179-190.

Torchinsky A, Fein A \& Toder V 1995b Immunoteratology: I. MHC involvement in the embryo response to teratogens in mice. American Journal of Reproductive Immunology 34 288-298.

Torchinsky A, Ivnitsky I, Savion S, Shepshelovich J, Gorivodsky M, Fein A, Carp H, Schwartz D, Frankel J, Rotter V, et al. 1999 Cellular events and the pattern of p53 protein expression following cyclophosphamide-initiated cell death in various organs of developing embryo. Teratogenesis, Carcinogenesis, and Mutagenesis 19 353-367.

Torchinsky A, Lishanski L, Wolstein O, Shepshelovich J, Orenstein H, Savion S, Zaslavsky Z, Carp H, Brill A, Dikstein R, et al. 2002 NF- $\kappa B$ DNA-binding activity in embryos responding to a teratogen, cyclophosphamide. BMC Developmental Biology 22.

Torchinsky A, Shepshelovich J, Orenstein H, Zaslavsky Z, Savion S, Carp H, Fain A \& Toder V 2003 TNF- $\alpha$ protects embryos exposed to developmental toxicants. American Journal of Reproductive Immunology 49 159-168.

Torchinsky A, Gongadze M, Orenstein H, Savion S, Fein A \& Toder V 2004 TNF- $\alpha$ acts to prevent occurrence of malformed fetuses in diabetic mice. Diabetologia 47 132-139.

Torchinsky A, Fein A \& Toder V 2005 Teratogen-induced apoptotic cell death: does the apoptotic machinery act as a protector of embryos exposed to teratogens? Birth Defects Research. Part C, Embryo Today 75 353-361. 
Torchinsky A, Gongadze M, Savion S, Fein A \& Toder V 2006 Differential teratogenic response of TNF $\alpha+/+$ and TNF $\alpha-/-$ mice to cyclophosphamide: the possible role of NF-кB. Birth Defects Research. Part A, Clinical and Molecular Teratology 76 437-444.

Wang B, Ohyama H, Haginoya K, Odaka T, Yamada T \& Hayata I 2000 Prenatal radiation-induced limb defects mediated by Trp53-dependent apoptosis in mice. Radiation Research 154 673-679.

Webster GA \& Perkins ND 1999 Transcriptional cross talk between NFкB and p53. Molecular and Cellular Biology 19 3485-3495.

Wilson JG 1977 In Handbook of Teratology: General Principles and Etiology, pp 47-74. Eds JG Wilson \& FC Fraser. New York: Plenum Press.
Wubah JA, Ibrahim MM, Gao X, Nguyen D, Pisano MM \& Knudsen TB 1996 Teratogen-induced eye defects mediated by 53-dependent apoptosis. Current Biology 6 60-69.

Zong WX \& Thompson CB 2006 Necrotic death as a cell fate. Genes and Development 20 1-15.

Received 17 February 2007

First decision 27 March 2007

Accepted 20 April 2007 